\title{
Using a wearable camera to support everyday memory following brain injury: a single-case study
}

\author{
Ali Mair ${ }^{1,2, *}$ (iD) and Rochelle Shackleton ${ }^{3}$ \\ ${ }^{1}$ Department of Psychology and Sports Sciences, University of Hertfordshire, Hatfield, UK, ${ }^{2}$ Department of Psychology, \\ University of York, York, UK and ${ }^{3}$ Community Rehabilitation Program, Wodonga Hospital, Albury Wodonga Health, \\ Albury, Australia \\ ${ }^{\star}$ Corresponding author. Email: ali.mair@york.ac.uk
}

(Received 30 September 2020; revised 08 January 2021; accepted 19 January 2021; first published online 16 March 2021)

\begin{abstract}
Background: Wearable cameras have been shown to improve memory in people with hippocampal amnesia and Alzheimer's disease. It is not known whether this benefit extends to people with amnesia of complex or uncertain origin.

Method: This case study examined the effect of wearable camera use on memory and occupational performance in a patient with memory loss and complex mental health problems following a severe neurological incident. With the help of his occupational therapist (OT), Mr A used a wearable camera to record a series of eight personally significant events over a 6-week period. During visits from his OT, Mr A was asked to report what he could remember about the events, both before (baseline) and during the review of time-lapsed photographs captured automatically by the camera.

Results: The results showed striking improvements in recall while reviewing the photographs, relative to baseline recall, but the additional details recalled during review did not appear to be maintained at later tests, after several days. Across the study period, there were moderate increases in occupational performance, measured using the Canadian Occupational Performance Measure. However, after the study period ended, $\mathrm{Mr}$ A ceased to use the wearable camera due to technological difficulty.

Conclusion: There was a clear benefit of wearable camera use, but the real-world impact of the technology was limited by the complexity of the system. The results of the study are discussed alongside novel clinical insights and suggestions for developing wearable camera support systems that can be used independently by people with memory problems.
\end{abstract}

Keywords: memory rehabilitation; episodic memory; autobiographical memory; amnesia; occupational therapy

Wearable cameras are small body-worn devices that capture still images or video footage automatically, from the wearer's perspective, providing an objective record of a personally experienced event, without any intervention from the wearer. Material captured by wearable cameras can be reviewed at a later point, and used to cue recollection of the events in question. Review of photographs captured by wearable cameras has been shown to improve memory for the reviewed events in people with hippocampal amnesia and Alzheimer's disease, and the memory support provided by these cameras is greater than the memory support provided by other means, such as reviewing a written diary (Berry et al., 2007; Browne et al., 2011; Loveday \& Conway, 2011; Pauly-Tackacs, Moulin, \& Estlin, 2011; Woodberry et al., 2015). Similar effects have also been observed in cognitively healthy young and older adults (Mair, Poirier, \& Conway, 2017, 2019; Sellen et al., 2007), and these findings have been documented systematically in a series of recent literature 
reviews (Allé et al., 2017; Arvola, Blomkvist, \& Wahlman, 2017; Chow \& Rissman, 2017; Dubourg, Silva, Fitamen, Moulin, \& Souchay, 2016; Silva, Pinho, Macedo, \& Moulin, 2016).

In addition to improvements in memory performance, the use of wearable cameras has also been associated with improvements in mental health outcomes in some patient studies. For example, following a wearable camera intervention, a reduction in depressive symptoms was observed in people with Alzheimer's disease (Silva et al., 2017), and a reduction in stress levels and increase in confidence was described in a patient with mild cognitive impairment (Browne et al., 2011). Increased confidence in social interactions was also described in another patient with hippocampal amnesia (Loveday \& Conway, 2011). These additional benefits may be mediated by memory improvements, or they may be a direct result of reviewing the photographs, which participants often describe as a pleasurable experience. In a study of healthy adults, participants rated their experience of reviewing wearable camera photos as more surprising, more exciting, more emotional and more helpful compared to reviewing written diary entries, and reported feeling more alert, remembering more and experiencing more episodic 'reliving' of their memories when reviewing the photographs (Silva, Pinho, Macedo, \& Moulin, 2013). In contrast, wearable camera use was not associated with any improvement in anxiety and depression symptoms in a patient with Korsakoff syndrome, who found the camera intrusive and resented that it reminded her of her memory impairment (Svanberg \& Evans, 2014), and did not improve anxiety or depression symptoms in a patient with acquired brain injury (Brindley, Bateman, \& Gracey, 2011), although recall improved in both cases. The factors contributing to the various non-memory outcomes in wearable camera studies, therefore, remain uncertain.

Despite increasing evidence of successful wearable camera memory support, only a small number of case studies have examined the effects in people with memory impairments. These studies predominantly involve patients with clear hippocampal pathology (e.g., Berry et al., 2007; Loveday \& Conway, 2011) or neurodegenerative disorders known to affect the hippocampus (e.g., Woodberry et al., 2015), and it is not clear whether the findings are generalisable to cases where memory deficits are the result of non-hippocampal or more widespread lesions, or of psychogenic or uncertain origin. Correspondingly, it is not known whether wearable cameras can also improve well-being of these patients.

This study examines the effect of wearable camera use on memory and occupational performance in a patient with severe anterograde memory impairment where the underlying pathology is unclear. The aim was to investigate whether reviewing wearable camera photographs led to improved event recall, thus extending the findings from hippocampal patients. We were also interested in whether there were any improvements in occupational performance (i.e., performance of everyday tasks) across the intervention period, which would indicate an increase in independence and participation. These outcomes are often associated with quality of life, mental health and caregiver burden (Goverover, Genova, Smith, Chiaravalloti, \& Lengenfelder, 2016; Jenkinson, Ownsworth, \& Shum, 2007; Magliano et al., 2000; Ormel, Rijsdijk, Sullivan, van Sonderen, \& Kempen, 2002; Waters, 1995).

\section{Case description}

$\mathrm{Mr} \mathrm{A}$ is a 48-year-old man who was hospitalised following a tonic-clonic seizure at home in 2017, approximately 18 months before the present investigation. Mr A's wife estimated that the seizure lasted around 1 minute. Mr A had no previous history of seizures. He was taken to the hospital by ambulance, and on admission had a Glasgow Coma Scale rating of 9. He was described as having prolonged postictal delirium, with aggressive behavior that lasted for 4 days. Mr A spent 1 month on the hospital's acute ward, where he continued to be confused and disorientated. The occupational therapist (OT) on the acute ward reported that Mr A had difficulty with new learning, orientation, recall, navigation, planning and processing, though a formal cognitive screen was 
not administered at that time. His notes describe both anterograde and retrograde amnesia, the latter characterised by the inability to remember anything since a birthday dinner 2.5 months before the seizure.

An MRI scan carried out 9 days post-seizure showed mild hyperintensity within the hippocampi in a symmetric distribution, posteriorly and bilaterally. This was interpreted by the radiologist as transient seizure-induced oedema due to neuroexcitation. The scan also showed hyperintensity in the left corona radiata, which was likely related to previous ischaemia, though no other site of previous infarction was identified.

During his time on the acute ward, the Westmead Post-Traumatic Amnesia Scale (WPTAS; Shores, Marosszeky, Sandanam, \& Batchelor, 1986) was administered daily in order to monitor $\mathrm{Mr}$ A's progress. The WPTAS is a verbally administered measure consisting of 12 questions examining orientation and new learning. It has been validated for use following closed head injuries and is not routinely administered post-seizure, but was administered in this case because a more appropriate measure was not available. Post-traumatic amnesia is considered to be ongoing until the respondent achieves a full score $(12 / 12)$ on three consecutive days. Mr A's scores showed a slow improvement, from 3/12 to 8/12 over a period of 1 month. By the end of the month, Mr A was able to remember the therapist's name, the location and the year, but had ongoing difficulty remembering the day and month, and remembering new pictures.

On discharge from the acute ward, $\mathrm{Mr}$ A spent 23 days in inpatient rehabilitation before being discharged and was referred to a community rehabilitation service for follow-up. Neuropsychological assessment was carried out approximately 4 months post-seizure, and showed severe deficits in visual and verbal episodic memory and executive function. Formal assessment and clinical observation of Mr A's memory showed a flat learning curve, indicating that his memory did not improve despite the repetition of information, and rapid forgetting. The results of the neuropsychological assessment are presented in Table 1.

A second MRI scan carried out at 5 weeks post-seizure showed slight bilateral hippocampal hyperintensity, though this was reduced compared to the first scan. The pattern of hyperintensity remained symmetrical, but there was no hippocampal restricted diffusion and no atrophy. The hyperintensity in the corona radiata was unchanged from the previous scan.

During investigation of the seizure, it was also noted that Mr A had suffered a traumatic brain injury (TBI) 30 years previously, though the location and nature of the damage and any effects on cognitive function were not well documented at the time. The previous TBI event had left Mr A with chronic post-traumatic stress disorder (PTSD), and he reported that prior to the seizure his PTSD symptoms had been getting progressively worse, with increasingly frequent nightmares and panic attacks. Mr A reported that for years before the seizure, he had not been getting out of bed and had not been eating properly, leading to significant weight loss. His medical notes showed a history of depression, and chronic pain for which he was prescribed opioid medication. $\mathrm{Mr}$ A also reported that he had been coping with depression by self-medicating, for example, taking 1 month's supply of prescribed medication in 1 week. He reported that he was not consuming alcohol or any other substances at that time.

Mr A completed compulsory schooling in Australia up to the age of 15, and had worked in a variety of jobs since the original TBI, including full-time and casual positions as a labourer, factory worker and salesperson, at times with supervisory responsibilities. However, he reported that he generally resigned from each position after a few months due to difficulties managing the organisational requirements of the different roles, as well as difficulties with fatigue, anger management, anxiety and time management. At the time of this investigation, Mr A reported that he was last employed approximately 20 years earlier, and had been largely confined to his house for the last 10 years.

Due to the complex combination of mental and physical difficulties experienced by $\mathrm{Mr} \mathrm{A}$, as well as the extended time frame over which his symptoms developed, it is difficult 
Table 1. Neuropsychological test scores at 4 months post-seizure

\begin{tabular}{|c|c|c|c|}
\hline Test & Subtest & Raw score & Percentile \\
\hline WIAT-II & Reading & 115 & $13^{\text {th }}$ \\
\hline \multirow[t]{6}{*}{ WAIS-IV } & Full-scale IQ & 80 & $9^{\text {th }}$ \\
\hline & General ability & 80 & $9^{\text {th }}$ \\
\hline & Verbal comprehension & 85 & $16^{\text {th }}$ \\
\hline & Perceptual reasoning & 81 & $10^{\text {th }}$ \\
\hline & Working memory & 86 & $18^{\text {th }}$ \\
\hline & Processing speed & 84 & $14^{\text {th }}$ \\
\hline \multirow[t]{2}{*}{ Digit span } & Forwards & 4 & $<1^{\text {st }}$ \\
\hline & Backwards & 5 & $50^{\text {th }}$ \\
\hline \multirow[t]{6}{*}{ WMS-IV } & Logical memory: I & 11 & $1^{\text {st }}$ \\
\hline & Logical memory: II & 0 & $<1^{\text {st }}$ \\
\hline & Logical memory: recognition & $18 / 30$ & $3^{\text {rd }}-9^{\text {th }}$ \\
\hline & Visual reproduction I & 26 & $5^{\text {th }}$ \\
\hline & Visual reproduction II & 0 & $<1^{\text {st }}$ \\
\hline & Visual reproduction: recognition & $3 / 7$ & $3^{\text {rd }}-9^{\text {th }}$ \\
\hline \multirow[t]{5}{*}{ HVLT-R } & Immediate recall: Trial 1 & $4 / 12$ & $2^{\text {nd }}$ \\
\hline & Immediate recall: Trial 2 & $8 / 12$ & $16^{\text {th }}$ \\
\hline & Immediate recall: Trial 3 & $5 / 12$ & $<1^{\text {st }}$ \\
\hline & Delayed recall & 1 & $<1^{\text {st }}$ \\
\hline & Recognition discrimination & 5 & $<1^{\text {st }}$ \\
\hline \multirow[t]{2}{*}{ Trail making } & Part A & 24 seconds & $70^{\text {th }}-80^{\text {th }}$ \\
\hline & Part B & 105 seconds & $<10^{\text {th }}$ \\
\hline \multirow[t]{2}{*}{ Rey Complex Figure } & Copy & 36 & $99^{\text {th }}$ \\
\hline & Immediate recall & 3 & $1^{\text {st }}$ \\
\hline Verbal fluency & FAS (total) & 19 & $<10^{\text {th }}$ \\
\hline Semantic fluency & Animals & 13 & $<10^{\text {th }}$ \\
\hline
\end{tabular}

to disentangle the effects of each condition on his cognition. His medical notes state that his memory had been deteriorating in the 3 years prior to the seizure, but became markedly worse post-seizure, and despite some improvement over time, had not returned to pre-seizure levels. Episodic memory impairment, including rapid forgetting, is a common outcome of TBI (Vakil, Greenstein, Weiss, \& Shtein, 2019; Vanderploeg, Donnell, Belanger, \& Curtiss, 2014), and poor episodic memory performance has frequently been described in people with PTSD (Isaac, Cushway, \& Jones, 2006), depression (McDermott \& Ebmeier, 2009; Söderlund et al., 2014) and anxiety disorders (Airaksinen, Larsson, \& Forsell, 2005). In addition, memory impairments are common in patients with seizures, whether epileptic or nonepileptic in origin (Helmstaedter, 2002; Lelliott \& Fenwick, 1991). Thus, Mr A's memory deficit at the time of this investigation could be the result of any combination of these conditions. Data for the present investigation were collected in December 2018 and January 2019. Prior to the start of this investigation, Mr A had tried using a written diary to help him remember, but he found it difficult and 
frustrating, and consequently did not use it consistently. As part of his community rehabilitation, his OT had attempted to use photographs to prompt his memory, and felt that the visual input was helpful, but was concerned that using a hand-held camera or mobile phone would be challenging. It was Mr A's OT who identified him as a potential beneficiary of wearable camera memory support.

\section{Method}

Data were collected by Mr A's OT as part of the routine care he received from his community rehabilitation team, and data collection was therefore designed to fit around the patient's usual activities and twice-weekly scheduled OT visits. Informed consent was obtained from both $\mathrm{Mr} \mathrm{A}$ and his wife prior to data collection. Ethical approval for this study was granted by Albury Wodonga Human Research Ethics Committee (HREC ref: ERM/51044, AWHREC ref: 444/19/1)

\section{Design}

The main outcome variable in this study was the number of details Mr A recalled about a series of personally experienced events. This outcome measure was selected for its ecological validity. The study followed a simple $\mathrm{AB}$ design, in which Mr A's baseline (free recall) performance for each event was measured first, before Mr A saw any wearable camera photographs, and cued recall for each event was measured immediately afterwards, during photograph review. The cued recall score was the number of new details recalled during photograph review that was not recalled during free recall.

\section{Materials}

Mr A used a FrontRow wearable camera (www.frontrow.com), which is a small $8 \mathrm{MP}$ touchscreen camera that can be worn on a lanyard around the neck or clipped to clothing. It has a wide-angle field of view of $148^{\circ} \pm 3^{\circ}$, and three modes of capture: single image, time-lapsed still images and video. In this study, we used the time-lapse mode, which is functionally similar to the wearable cameras used in previous studies (e.g., Mair et al., 2017). Within the time-lapse mode, the rate of photo capture could be adjusted using a digital slider, which sets the camera to take a photograph at variable intervals ranging from 'fast' to 'slow' (the intervals are not stated in seconds). In addition, the use of inbuilt motion sensors causes the rate of photo capture to vary within a single recording, such that the precise rate of capture cannot be fixed. Here, we used the 'bicycle' setting - towards the faster end of the scale - which pilot testing showed to capture photographs at intervals of between 6 seconds and 13 seconds ( $M=11.5$ seconds). Since the capture rate cannot be reliably specified in advance, we instead report the average rate of capture for each activity in the results section.

\section{Procedure}

With the help of his wife, Mr A used the wearable camera to record a series of eight personally meaningful events over a 6-week period. He was instructed to record pleasant or routine 'memorable events', defined as activities that he would want to remember later, that had a clear start and end point. During follow-up visits by his OT, he was asked first to recall the activities he had recorded in response to only the title of the event (free recall), and immediately afterwards, he reviewed photographs of the event and was asked concurrently to report any additional details he could remember (cued recall). We were interested in whether Mr A was able to recall new details while reviewing the photographs. 
Table 2. Schedule of events recorded, recalled and reviewed by $\mathrm{Mr} \mathrm{A}$

\begin{tabular}{|c|c|c|c|c|c|c|c|c|c|c|c|c|c|}
\hline & 1 & 2 & 3 & 4 & $5^{\#}$ & 8 & $9^{\#}$ & $12^{\#}$ & $15^{\#}$ & $18^{\#}$ & $22^{\#}$ & $25^{\#}$ & 39 \\
\hline Event recorded & A & B & C & & $\mathrm{D}$ & & $\mathrm{E}$ & $\mathrm{F}$ & & G & $\mathrm{H}$ & & \\
\hline \multirow[t]{4}{*}{ Free recall } & & & & A & & B & & B & & & & D & ALL \\
\hline & & & & B & & $D$ & & D & & & & $\mathrm{F}$ & \\
\hline & & & & C & & & & & E & & & $\mathrm{G}$ & \\
\hline & & & & & & & & & $\mathrm{F}$ & & & $\mathrm{H}$ & \\
\hline \multirow[t]{4}{*}{ Cued recall } & & & & A & & B & & & B & & & $\mathrm{D}$ & \\
\hline & & & & B & & $\mathrm{D}$ & & & D & & & $\mathrm{F}$ & \\
\hline & & & & $C$ & & & & & E & & & G & \\
\hline & & & & & & & & & $\mathrm{F}$ & & & $\mathrm{H}$ & \\
\hline
\end{tabular}

\#Indicates a break in the schedule; days on which there were no activities have been omitted from the visualisation

Photographs were reviewed on a laptop computer, in forward order, and the full set of images was reviewed for each recorded event. There is currently no standard procedure for reviewing wearable camera photos, though the slow or self-paced review is usually favoured because it allows the participant time to examine the images in detail. However, Woodberry et al. (2015) reported that patients with Alzheimer's disease felt they benefitted from an additional opportunity to review the photographs quickly, in a time-lapse movie. In the current study, photos were therefore reviewed at two different speeds, following Woodberry et al. The fast sequence ( 6 frames per second) was presented first to introduce the event to $\mathrm{Mr} \mathrm{A}$, and this was immediately followed by a slow presentation ( 1 frame per second) of the same images. During the slow presentation, Mr A was permitted to pause the playback, return to previous images and skip through less informative images more quickly, if he chose to. The entire review session was audio-recorded, and any details recalled during the review at either speed were counted towards the total for cued recall. In practice, Mr A did not recall any details during the fast presentation, but because we did not formally distinguish between details recalled during the fast and slow review, the fast review could still have contributed to overall performance.

Originally we intended for Mr A to record 10 activities, 4 of which would be reviewed 3 times, and 6 of which would be reviewed only once, allowing us to measure whether memory improvements were affected by the number of opportunities to review. However, Mr A cancelled 4 out of the 11 scheduled OT visits during the study period, resulting in a schedule of recording and reviewing that was more irregular than planned. The actual schedule of recorded and reviewed events is presented in Table 2. Eight activities were recorded in total. Five of these activities were reviewed only once, one activity was reviewed twice, and two activities were reviewed three times. Finally, in the sixth week of the data collection phase, Mr A was asked to freely recall all eight events again. All recall attempts were verbal, in free narrative form.

\section{Data processing}

Audio files were transcribed and coded to determine the number of details recalled on each occasion. The coding protocol was data-driven, and we distinguished between 11 different types of detail. Descriptions of the 11 categories are available in the Appendix (Table A1), but for the purpose of this investigation, only episodic details were examined. Episodic details were defined as stand-alone ideas, usually expressed as a single phrase, and which described a specific aspect of the event in question (e.g., 'I remember that I drove there', 'I drank a lot of water'). Sixteen transcripts (eight free recall and eight cued recall) were second coded by an independent rater blind to the hypothesis, and the inter-rater reliability between first and 
second coders was calculated. There was excellent agreement between raters for the number of episodic details (Cronbach's $\alpha=0.96$ ). The independent rater coded for all 11 detail categories; the results of the additional analyses are available on the Open Science Framework project page (https://osf.io/3jpuc/).

\section{Activity participation}

We were also interested in whether wearable camera use affected Mr A's participation in daily activities during the study period. At the beginning of the 6-week data collection phase, two occupational performance measures were administered: the Canadian Occupational Performance Measure (COPM $-5^{\text {th }}$ version; Law et al., 1990), an occupational therapy tool which measures the client's self-perception of performance in everyday living and the Frenchay Activities Index (FAI; Holbrook \& Skilbeck, 1983), which measures the client's functional status (that is, their ability to perform certain activities related to lifestyle, e.g., preparing meals, social activities).

The COPM is a multi-step scale, in which the client first identifies problems they are having in the domains of self-care, productivity and leisure, and then rates the importance of each problem on a scale of 1-10. Based on these importance ratings, the five most urgent problems are identified, and for each, the client then rates their own ability to perform the activities on a scale of 1-10, and their satisfaction with their own performance on a scale of 1-10. Performance scores for all five problems are averaged to give an overall performance score of between 1 and 10, and the same calculation is performed for satisfaction scores. These ratings are taken again post-intervention, and pre- and post-intervention scores are compared. A change of two points or more is considered to be clinically significant (Law et al., 1991). The measure is valid for use with patients with brain injury, and has adequate test-retest reliability in this group (Jenkinson et al., 2007).

The FAI comprises 15 items, which are given frequency ratings of $0-3$ either by the client or their caregiver. Items consist of domestic, outdoor and leisure activities (e.g., preparing meals, housework, social outings, reading books). For each item, a rating of 0 denotes the lowest frequency (never/none), while a rating of 3 denotes the highest frequency (which varies by item, e.g., most days/at least weekly/over 30 hours per week). The total score on the scale, therefore, ranges from 0 to 45 . The test is reliable in people with brain injury $(I C C=0.87$; Van Baalen et al., 2006). The pre-intervention FAI was completed separately by $\mathrm{Mr} \mathrm{A}$, and by his wife acting as a proxy, so that scores could be compared.

The COPM was administered again at the end of the 6-week study period. We were unable to administer the FAI in the same session due to time constraints following the cancellation of one of the two final study sessions, which meant all tests had to be completed in a single session, and $\mathrm{Mr}$ A became fatigued. Mr A's wife was not available during this session, and therefore could not complete the FAI either. The FAI was administered for the second time 3 months after the end of the study, but due to a dip in Mr A's mental health at this time, we were only able to collect proxy scores from his wife.

\section{Results}

Details of the recorded events and the rate of photo capture for each event are presented in Table 3.

\section{Baseline free recall}

Mr A's recall at baseline varied across the recorded events, but was generally low (see Fig. 1; number of episodic details: $M=4.13, S D=5.74$; range $=0-17$ ). For three of the eight events, he could not recall any details on the first attempt despite the relatively short retention interval between encoding and retrieval $(M=3.33$ days, $S D=2.52)$. For four of the events, some details were recalled. The retention interval for these four events was similar to the interval for those events 
Table 3. Details of the eight recorded events

\begin{tabular}{|c|c|c|c|c|}
\hline $\begin{array}{l}\text { Event } \\
\text { ID }\end{array}$ & Event title & $\begin{array}{l}\text { Event duration } \\
\text { (minutes) }\end{array}$ & $\begin{array}{l}\text { Photos-per-minute } \\
\text { (mean) }\end{array}$ & $\begin{array}{c}\text { Mean interval } \\
\text { between photos }(s)\end{array}$ \\
\hline A & Walking around the park & 22 & 6.33 & 9.48 \\
\hline B & Picking up the new dog & 79 & 6.29 & 9.60 \\
\hline C & Getting takeaway & 10 & 6.72 & 8.93 \\
\hline D & Dinner at restaurant $A$ & 97 & 7.47 & 8.03 \\
\hline $\mathrm{E}$ & Dinner at restaurant B & 36 & 7.78 & 7.71 \\
\hline $\mathrm{F}$ & Christmas lunch with family & 156 & 6.87 & 8.74 \\
\hline G & Picking up wife's new dog & 75 & 5.83 & 10.30 \\
\hline $\mathrm{H}$ & Getting petrol and takeaway & 19 & 4.37 & 13.73 \\
\hline
\end{tabular}

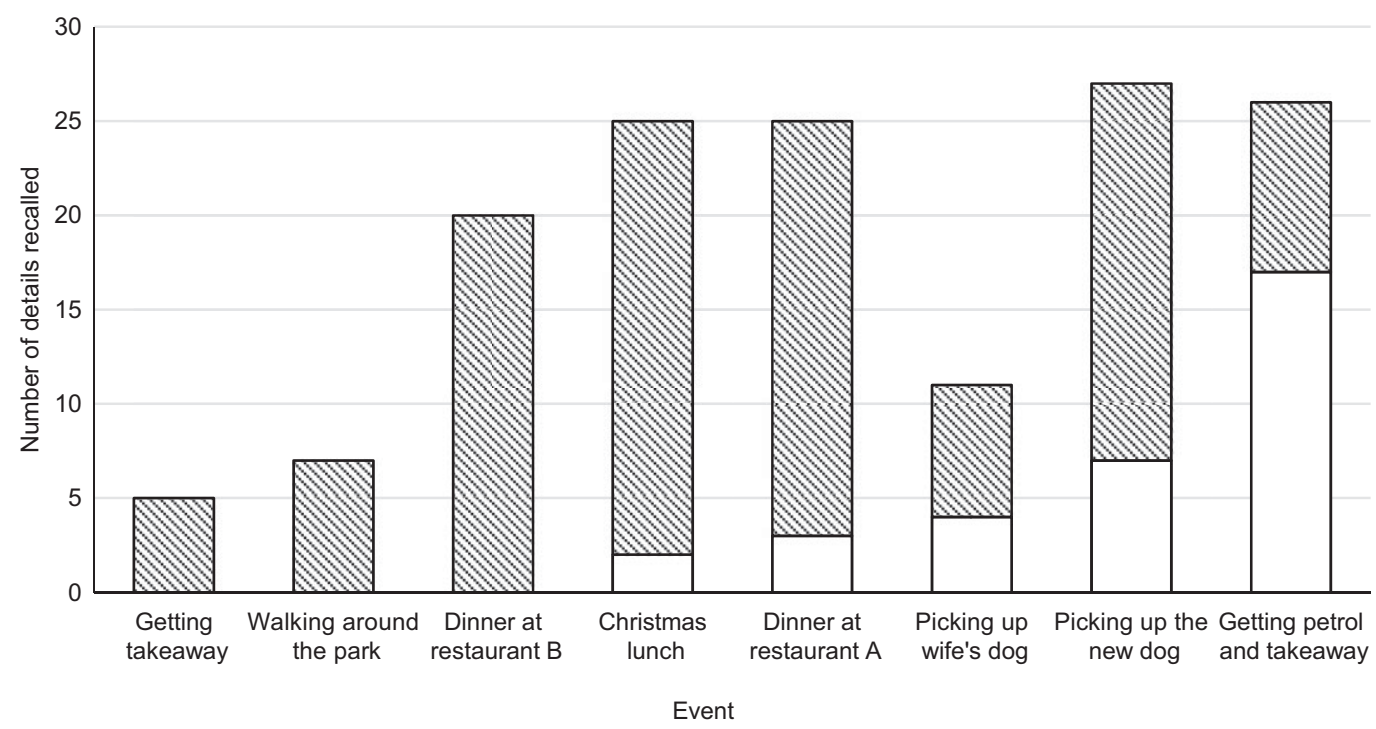

$\square 1$ st attempt $\quad$ 1st attempt

Figure 1. Number of details recalled in the first free recall attempt (white bars) and subsequent first photo-cued recall attempt (striped bars) of each event. Note: To facilitate visualisation, events have been re-ordered and are presented in ascending order by the number of details recalled during free recall, rather than the order in which they were sampled.

that were not recalled at all $(M=3.75$ days, $S D=2.22$ days $)$. The number of recalled details was not correlated with event duration $(r=-0.13, p=0.76)$. The events probably varied in memorability due to the nature of the activity that was recorded: one event was recalled in much more detail than the other seven, and this event was particularly distinctive because it was the first time in the 18 months of OT intervention that Mr A had voluntarily and spontaneously left the house, and felt confident in doing so.

There was some categorical overlap of the sampled events, such that $3 / 8$ involved having a meal somewhere out of the house, $2 / 8$ involved going to pick up a new dog and 2/8 involved getting takeaway food (Table 3). During free recall, Mr A showed some difficulty in distinguishing between these categorically similar events. For example, during one of the family meals, there was a planned surprise, and during another of the meals, there was an announcement. When 


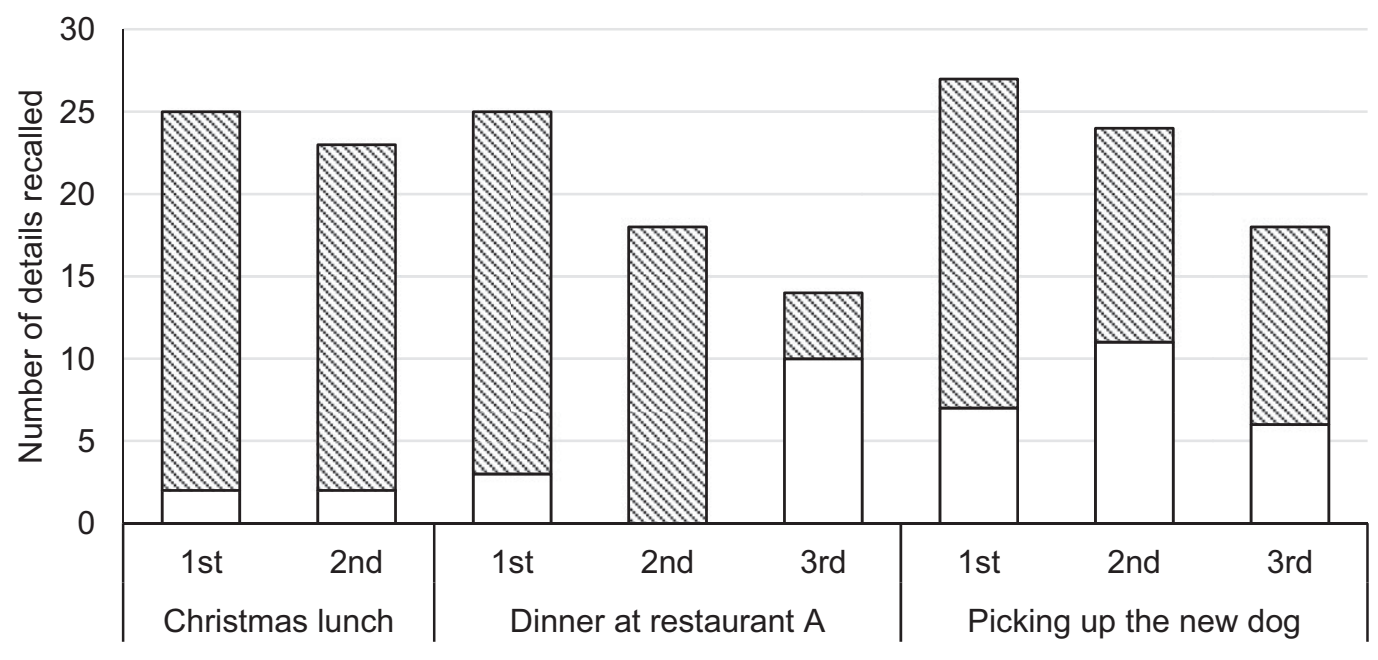

Event/review number

$\square$ free recall $⿴$ cued recall

Figure 2. Number of details recalled during free recall (white bars) and subsequent photo-cued recall (striped bars) of events for which there was more than one opportunity to review. Note: first/second/third denotes the order of sessions for each event, i.e., first attempt, second attempt, etc.

asked about one of the meals, Mr A recalled that something significant had happened, but could not recall what had happened and whether it had happened during the meal in question or during one of the other meals.

\section{Cued recall}

Photographs of all eight events were reviewed at least once, and the first review took place immediately following the first free recall attempt for that event. We recorded what $\mathrm{Mr} \mathrm{A}$ remembered while reviewing the images, and scored only the number of new episodic details that were reported during the review (i.e., only details that had not been reported during the free recall attempt immediately prior; details that had been reported in the prior free recall attempt were counted as repetitions in the cued recall attempt). The cued recall score was the sum of the free recall score and the new episodic details added during the review. The difference between free recall and cued recall scores was analysed using a Wilcoxon signed-ranks test, since the small number of observations precluded analysis with a parametric test.

When cued with the photographs from the wearable camera, Mr A recalled significantly more event details (see Fig. $1 ; M=14.13, S D=7.75$; range $=5-23 ; Z=2.53, p=0.01$ ). The percentage increase in recall compared to the original free recall score for each event was between $53 \%$ and $1150 \%(M=479 \%, \mathrm{SD}=454 \%$; note that percentage increase could not be calculated for the three events for which nothing was recalled during the free recall attempt). There was no clear relationship between the number of details recalled in the first free recall attempt and the number of new details that were reported during photo review $(r=-0.11)$, which suggests that the effect of reviewing the photographs was not heavily dependent on either the presence or absence of some recollection at baseline.

We also briefly examined the effect of reviewing the photographs more than once, since one of the events was reviewed twice and two were reviewed three times each. For each event, $\mathrm{Mr} \mathrm{A}$ recalled numerically fewer details in the later sessions compared to the earlier sessions (see Fig. 2), though with a sample size of only three events, the pairwise comparisons were not 


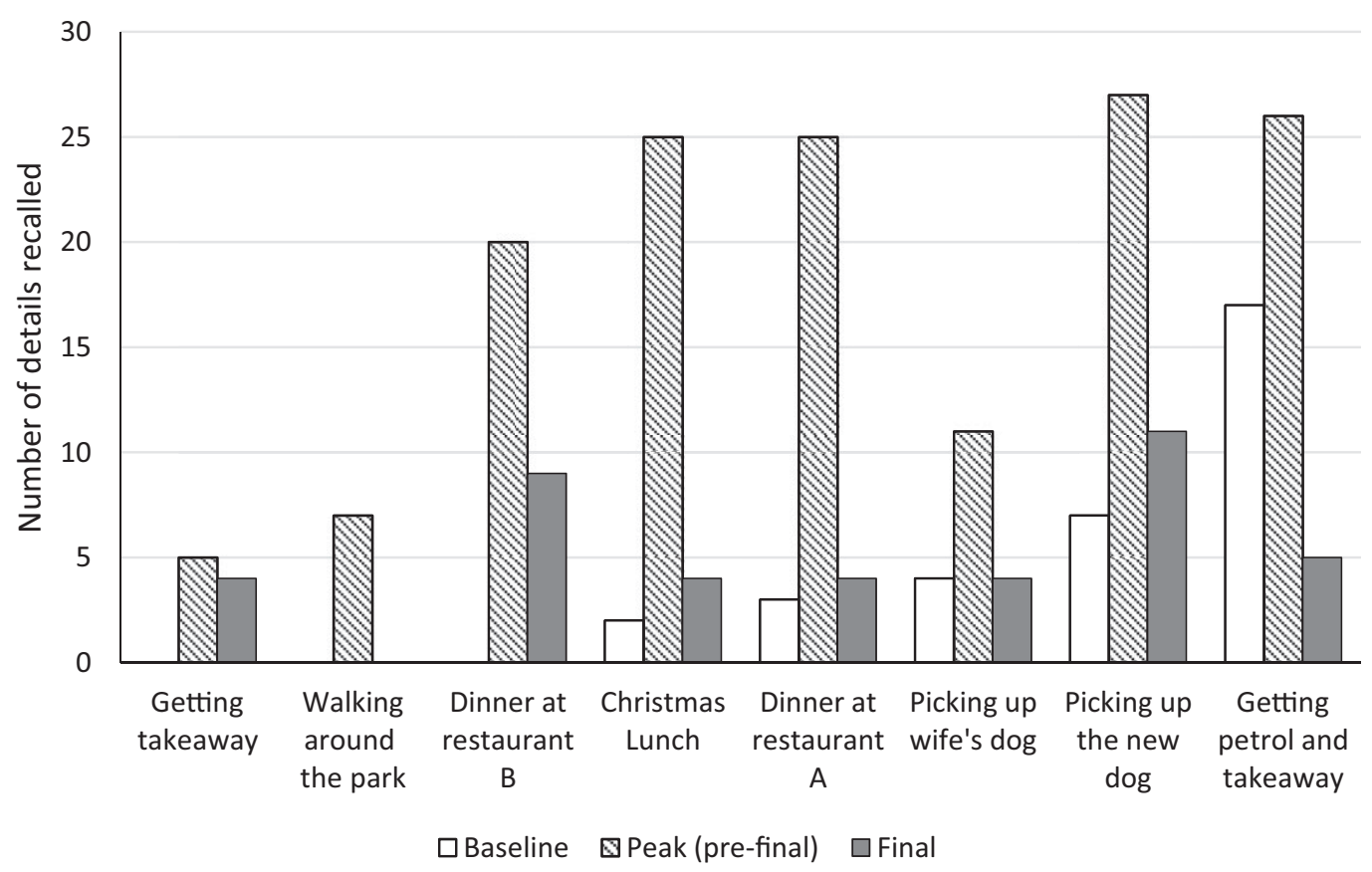

Figure 3. Number of details recalled at baseline, peak and at the final test. Note that for every event, peak recall performance was during the first time the photographs were reviewed.

statistically significant. While the number of details recalled during free recall was unstable, the effect of reviewing the photographs appeared to become progressively weaker over time.

\section{Consolidation}

We also investigated whether the additional details recalled while reviewing the photos were maintained during the final follow-up test on Day 39 (i.e., whether there was any evidence that Day 39 free recall was better than the initial free recall attempt for each event). Figure 3 presents the number of details recalled at baseline, during peak recall (for every event, this was during the first time the photos were reviewed), and at the final test. Final test performance was significantly lower than peak performance $(Z=2.39, p=0.02)$, but there was no significant difference between baseline and final test $(Z=0.95, p=0.34)$. Thus, although there was no evidence of consolidation, use of the wearable camera may have prevented further forgetting over the intervention period.

\section{Activity participation}

Occupational performance was measured pre- and post-intervention using the COPM. Overall, COPM scores post-intervention were higher than pre-intervention scores $(Z=2.01, p=0.04)$. Mr A's COPM performance score (his self-assessment of the extent to which he was able to perform important activities) rose by 0.8 , from $1.6 / 10$ pre-intervention to $2.4 / 10$ post-intervention. His satisfaction score (the extent to which he was satisfied with his ability to perform the activities) rose by 1.8 , from $1.6 / 10$ pre-intervention to $3.4 / 10$ post-intervention. These moderate increases should be interpreted with caution since there is no control condition for comparison. However, the changes in scores appear to show that Mr A's satisfaction increased more than his performance, which could be indicative of increased mental well-being if not so much functional ability. These changes fell short of the two points considered to be clinically meaningful; however, the 
Table 4. Pre- and post-intervention scores on the COPM

\begin{tabular}{llccc}
\hline & \multicolumn{2}{c}{ Performance } & & Satisfaction \\
\cline { 2 - 5 } Identified problems, in order of importance & Pre & Post & & Pre \\
\hline Going to wife's appointments with her & 1 & 3 & 1 & Post \\
\hline Going out for dinner with wife & 2 & 4 & 1 & 1 \\
\hline Meeting a friend out of town & 1 & 1 & 3 \\
\hline Cooking a meal & 3 & 3 & 3 \\
\hline Walking around the park & 1 & 1 & 2 \\
\hline
\end{tabular}

difference was driven by changes for the two most important goals. Here, his participation improved by two points and his satisfaction by four points (see Table 4).

Pre-intervention, Mr A's self-rated FAI score was 8/45, while his wife's rating was 11/45. As noted above, the FAI could not be completed immediately post-intervention, and repeat administration took place with Mr A's wife only. At 3 months post-intervention, Mr A's wife's FAI rating had dropped to $8 / 45$. This drop was not statistically significant $(Z=-1.00$, $p=0.32$ ), and corresponded to half the minimal detectable change for this measure (six points). It is, therefore, not known whether there was any improvement in FAI score during the intervention period, but if there was improvement then this had been lost after the camera ceased to be used.

\section{Clinical insights}

Because wearable camera memory support is an emerging area of research, and relatively little has been published about the challenges of the everyday application of this technology, we note some interesting insights generated by $\mathrm{Mr} \mathrm{A}$, his wife and his OT. There was consensus among all three that using the wearable camera as a rehabilitation intervention was a positive experience. The camera was well accepted by $\mathrm{Mr} \mathrm{A}$, who did not report feeling self-conscious wearing it in public. His acceptance was perhaps aided by the appearance of the FrontRow device, which does not look like a typical camera. Mr A's wife (who was present during some of the recall attempts) was enthusiastic about the memory support provided by the camera, and his OT was surprised by how much he was able to remember. In the 18 months that she had worked with him before the study period, his OT had observed that he was generally unable to recall what he had done the previous day, or earlier the same day, so his retention of some memory details at the final test, up to 6 weeks post-event, was seen as an important outcome

His OT also observed a positive effect of the camera on Mr A's mental health and social participation, including a perceived reduction in his anxiety and rumination, an increase in motivation and a lessening of the hypervigilance associated with his PTSD. These positive effects may have been the result of the camera enabling $\mathrm{Mr} \mathrm{A}$ to reflect on recent positive experiences rather than ruminating on previous negative experiences. Mr A himself believed that using the camera had given him confidence and made him feel less insecure. In an interview with his OT after the intervention, he described how his memory problems made him feel socially disconnected:

“It sucks. I'm not connected to nothing. I've lost that personal relationship. Like we've built up a rapport now, you know, of us getting to know each other, but I still feel insecure because I don't remember half the shit that we've spoken about... [but the camera helps] put things in perspective, and put some things in order." 
Mr A had previously described having trouble keeping up with conversations in a group setting. In the post-intervention interview, however, he described how the knowledge that the camera was automatically recording the experience had enabled him to focus on 'the now' during social interactions, because 'I can just try and follow you, if I lose you, let it go, try and pick up just what I can and then go back to the information [later]'. He said that his wife and another family member had commented on his increased engagement in conversation, and had told him that he was repeating himself less and getting things mixed up less frequently. The observations about increased confidence in social interactions echo similar comments made by participants in previous studies (Browne et al., 2011; Loveday \& Conway, 2011).

$\mathrm{Mr}$ A also described how the opportunity to use the camera had been motivational. He said: 'It's made me get off my arse and think about what I can do that's going to be useful for this, [rather] than just sitting in the bed looking at the wall, or watching TV'. However, he was less sure of the effect of the camera on his memory. When asked whether he thought it had helped his memory, he said: 'I can't really see how, but it's made me try $100 \%$ harder and think a lot more deeper'. The final event $\mathrm{Mr}$ A recorded during the study period was a significant occasion, since it was the first time in 18 months that he had spontaneously and voluntarily left the house to carry out an activity on his own, and had felt confident in doing so. On previous occasions when he had been out alone, he reported feeling very anxious while out. His OT believed the independence he displayed in this final event was a sign of the increased confidence he had developed through using the camera.

However, on more than one occasion, Mr A reported a 'sense of dread' when reviewing photographs of things he did not remember. It is possible that this feeling was worsened by the experimental context - that is, because he knew he would be asked to recall the details of the event aloud. Similar comments were made by a participant in a previous study, who reported that they did not like being reminded of things they could not remember, when reviewing a written diary (Woodberry et al., 2015). The discomfort of this situation might be alleviated by reviewing the photos for the first time after a shorter delay, when it is more likely that some of the event details are still retained in memory (e.g., at the end of the same day). However, further research is needed to address this possibility directly, particularly since the end-of-day review was found to be ineffective in a large sample of healthy participants (Seamon et al., 2014).

After the intervention period, the camera was left with Mr A. His OT had provided him with comprehensive instructions for recording events and downloading and reviewing the photographs, but after a few unsuccessful attempts, Mr A became frustrated. His confidence was negatively impacted, and he stopped attempting to use the camera. Although Mr A appeared to show some signs of increasing independence while using the camera, he was ultimately unable to progress without the continued support of his OT.

\section{Discussion}

The results showed a clear positive effect of reviewing the wearable camera photos on Mr A's episodic memory. A striking retrieval benefit was observed during photo review, similar to the benefit reported in patients with hippocampal amnesia (e.g., Loveday \& Conway, 2011), thus showing that previous findings extend beyond cases with a clear hippocampal origin. In addition to the retrieval benefit, there was some evidence that the use of the wearable camera had a positive impact on Mr A's mental health. This was indicated by improved performance and satisfaction scores on the COPM, which was consistent with his own report, post-intervention, of increased motivation and confidence in social interactions.

However, it was uncertain whether memory consolidation was supported by photo review. On one hand, baseline recall performance was maintained at the final test, despite an interval of between 2 and 5 weeks between the two attempts; over such timescales, some forgetting is likely 
under normal circumstances. On the other hand, without a no-photo control condition, it is not possible to determine how much forgetting was to be expected, and consequently, it is not known whether the earlier photo review attenuated forgetting at the final test. Another complicating factor was that $\mathrm{Mr}$ A's recall was negatively affected by fatigue, and his performance at final test may have been poorer than earlier in the intervention due to the requirement for him to recall all eight events in a single session.

The findings suggested that the beneficial effect of reviewing the wearable camera photographs was greatest the first time the photographs were reviewed, and diminished thereafter. There are at least two alternative explanations for this pattern. First, if the power of the photographs to cue memory depends on the availability of an underlying 'organic' memory trace, and if that memory trace can be understood to deteriorate over a relatively short time, then the diminishing cueing power of the photographs could be the direct result of the reduced availability of the underlying trace (i.e., there is less memory available to cue). Alternatively, the cueing power of the photographs could be reduced by repetition if, for example, the repetition caused the association between the cues and the original experience to weaken. This explanation would not require deterioration of the underlying 'organic' memory trace, but instead would indicate that the repetition of the same set of cues rendered the memory less accessible in later sessions (see Tulving \& Pearlstone, 1966 for a discussion of memory availability vs. accessibility). If this were the case, memory might be enhanced in later sessions by presenting different subsets of photographs on different occasions, to minimise repetition. In any case, since such diminishing returns are clearly a matter of applied relevance, this would be an interesting avenue for further research.

In the present study, the frequency of review sessions was dictated by the frequency of scheduled visits from Mr A's OT, who administered the intervention as part of Mr A's routine care. His OT believed there may have been a greater memory benefit with more regular photo review and shorter gaps between sessions, similar to the procedure described by Woodberry et al. (2015), in which events were reviewed every two days. Indeed, a more intensive schedule may have been more effective if shorter intervals led to less forgetting between sessions, and enabled $\mathrm{Mr} \mathrm{A}$ on each occasion to build on the memory from the previous session. Presumably, this would be the case if the primary issue was the availability of the underlying memory trace, as described above. However, it is not clear, given the neuropsychological data on the nature of Mr A's memory impairment (i.e., the flat learning curve), that more intensive reviewing would have had a proportional benefit for Mr A. Future work could investigate different schedules of photo review, to establish the effect of review frequency on retrieval benefit.

In the present study, more frequent review sessions would have required $\mathrm{Mr} \mathrm{A}$ to be able to review the photographs without support. This was not possible because the technological complexity of the wearable camera system was a major barrier preventing Mr A from using the camera independently. Although such devices are typically designed to be user-friendly, developers may not consider people with memory impairments to be the target audience. Mr A's difficulty using his camera highlights the need for future wearables to be designed in consultation with patients if they are to become viable rehabilitation options. Ideally, wearable cameras should increase the independence of the user without increasing the time invested by the therapist or caregiver.

\section{Barriers preventing independent use}

Although wearable cameras are designed to work intuitively, the inclusion of a broad suite of features in newer devices aimed at the general population comes at the expense of the increased complexity of operating the camera. For example, the device used in this study had a button that could be pressed and held to record video, pressed once for a single photo and pressed twice for a time-lapse photo; a further button press paused the photo capture. Although this presents the user with a range of camera functions, this type of multi-function button can be challenging when unfamiliar, and maybe particularly problematic for people with even minor deficits in fine motor 
control, learning, memory and attention. In this case, the problem was compounded by the fact that it was not easy to tell whether the camera was working as intended until afterwards, when $\mathrm{Mr}$ A tried to review the photographs. Although the camera status was displayed on screen, it was difficult for Mr A to see without his glasses. Several times, when attempting to review the photographs, it transpired that the camera had taken a single photo instead of a sequence of time-lapse photos. This means that important events that one is keen to record can easily be missed, which can be disappointing.

In addition, the process involved in downloading and reviewing photographs involved multiple steps and extra equipment (e.g., a laptop). For example, once the camera was connected to the laptop, Mr A had to locate and open the relevant folder, cut and paste the required files to a new directory, and rename the files with a date and title that would help him to find them later. Remembering to how to complete a series of steps in the correct order can prove challenging for people with memory problems, particularly if they also lack confidence and familiarity with computers. Transfer is typically via a USB cable, or in some models of the camera by Bluetooth or Wi-Fi connection. On Mr A's camera, there was an option to connect the camera to a smartphone application, which, once set up, would have required fewer steps. However, the smartphone screen would have been too small to see the photos clearly, Mr A was not confident using his smartphone for applications other than phone calls and messaging, and there was concern about the ease of accidentally live streaming the images via social media. This option was therefore not useful.

\section{Suggestions for improved accessibility}

Based on the above observations, our suggestions for improving the accessibility of wearable cameras for target populations are twofold. First, the camera itself should have a single button with a single function - to switch it on and off - and a clear indicator showing which state the camera is in. This suggestion is modelled on early wearable cameras such as Microsoft's SenseCam and Vicon's Revue, which had fewer features but were simpler to operate. The simplicity of a single-function button clearly comes at the expense of the flexibility of function that may be of interest to a more commercial audience, but our view is that this is a necessary trade-off for wearable cameras to be useable by target groups.

Our second suggestion concerns the process of reviewing the photographs captured by wearable cameras. In our opinion, the ideal solution would be a closed system designed specifically for the purpose of reviewing photos. Such a system would comprise a wearable camera and separate viewing screen, sold together, which can communicate with each other automatically (or in response to a button press on the viewing screen) via a wireless connection. The viewing screen should, by default, not connect to any other hardware device or software application and should have a limited number of controls that are always visible without having to navigate a menu system. Such controls might include a search function to enable the selection of an event for review, a play/pause button, playback speed control and the option to delete an unwanted event. This closed system would eliminate four potential problems: (1) the requirement for the user to understand how to connect the camera to another device, (2) the need to keep track of a connecting cable, which is easy to lose, (3) the requirement for the user to learn to navigate a menu of choices and (4) the risk of inadvertently sharing personal data. A fifth potential problem is the requirement for the user to navigate a file storage system. To address this, recorded events could be automatically titled using photo metadata such as the date, time and GPS location, and indexed using a familiar interface such as a searchable visual calendar or map, similar to the Timeline feature on Google Maps. The simplicity of such a closed system would reduce the customisation options available to the user, but an administrator-level account could be an option to allow a caregiver to customise the device according to the user's preferences. 
Addressing these issues should not be technologically difficult: some previous wearable cameras (e.g., Vicon Revue) provided software for automatically importing and organising streams of photographs, and there are ongoing developments on the issue of managing and designing interfaces for large numbers of wearable camera photographs in the field of computer science (e.g., Caprani et al., 2010; Duane \& Gurrin, 2020; Lee et al., 2008). Thus, our suggestions are concerned less with novel technological developments, and more with the overarching need to prioritise simplicity over breadth of features. We suggest that this might be best achieved by bringing together a number of existing technologies in a system designed with simplicity in mind.

\title{
Conclusion
}

The case of Mr A provides further evidence for the effectiveness of wearable cameras as memory aids for people with memory impairments. Together with previous research, the results presented here show the potential for striking improvements in recall supported by wearable cameras. In its current state, the technology appears to have the capacity to improve the everyday lives of people with memory impairments, and may improve well-being in some people, however, urgent attention must be directed at the development of devices that can be used independently by people in the target population, without the need for caregiver oversight.

\begin{abstract}
Acknowledgements. We would like to thank Mr A for participating in this case study, and Mr A's wife for providing the support required to enable Mr A to participate. We would also like to thank Lauren Carter at the University of York for her help in second coding the memory transcripts. We would like to thank Anna Moran and Leah Wiseman at Albury Wodonga Health for providing guidance with the ethics application and advice on the clinical research process. We would like to thank Aleksandra Tarnawski at the South West Brain Injury Rehabilitation Service (Murrumbidgee Local Health District) for providing and interpreting Mr A's neuropsychological assessment scores. We would like to thank Professor Andy Young at the University of York for his feedback on an earlier draft of the manuscript.
\end{abstract}

Financial support. This work was supported in part by a Postdoctoral Fellowship award from the British Academy (Grant number: PF19\100083).

Conflicts of interest. None.

Ethical standards. The authors assert that all procedures contributing to this work comply with the ethical standards of the relevant national and institutional committees on human experimentation and with the Helsinki Declaration of 1975, as revised in 2008 .

\section{References}

Airaksinen, E., Larsson, M., \& Forsell, Y. (2005). Neuropsychological functions in anxiety disorders in population-based samples: Evidence of episodic memory dysfunction. Journal of Psychiatric Research, 39(2), 207-214.

Allé, M. C., Manning, L., Potheegadoo, J., Coutelle, R., Danion, J.-M., \& Berna, F. (2017). Wearable cameras are useful tools to investigate and remediate autobiographical memory impairment: A systematic PRISMA review. Neuropsychology Review, 27(1), 81-99.

Arvola, M., Blomkvist, J., \& Wahlman, F. (2017). Lifelogging in user experience research: Supporting recall and improving data richness. The Design Journal, 20(supp 1), S3954-S3965.

Berry, E., Kapur, N., Williams, L., Hodges, S., Watson, P., Smyth, G., . . Wood, K. (2007). The use of a wearable camera, SenseCam, as a pictorial diary to improve memory in a patient with limbic encephalitis: A preliminary report. Neuropsychological Rehabilitation, 17(4/5), 582-601.

Brindley, R., Bateman, A., \& Gracey, F. (2011). Exploration of use of SenseCam to support autobiographical memory retrieval within a cognitive-behavioural therapeutic intervention following acquired brain injury. Memory, 19(7), 745-757.

Browne, G., Berry, E., Kapur, N., Hodges, S., Smyth, G., Watson, P., \& Wood, K. (2011). SenseCam improves memory for recent events and quality of life in a patient with memory retrieval difficulties. Memory, 19(7), 713-722.

Caprani, N., Doherty, A. R., Lee, H., Smeaton, A. F., O’Connor, N. E., \& Gurrin, C. (2010). Designing a touch-screen SenseCam browser to support an ageing population. CHI EA'10: CHI'10 Extended Abstracts on Human Factors in Computing Systems, 4291-4296. doi: 10.1145/1753846.1754141

Chow, T. E., \& Rissman, J. (2017). Neurocognitive mechanisms of real-world autobiographical memory retrieval: Insights from studies using wearable camera technology. Annals of the New York Academy of Sciences, 1396, 202-221. 
Duane, A., \& Gurrin, C. (2020). Baseline analysis of a conventional virtual reality lifelog retrieval system. In Y. Ro, W-H. Cheng, J. Kim, W-T. Chu, P. Cui, J-W. Choi, ... W. De Neve (Eds.), Multimedia Modeling. MMM 2020. Lecture Notes in Computer Science (Vol. 11962). Cham: Springer. doi: 10.1007/978-3-030-37734-2_34

Dubourg, L., Silva, A. R., Fitamen, C., Moulin, C. J. A., \& Souchay, C. (2016). SenseCam: A new tool for memory rehabilitation? Revue Neurologique, 172(12), 735-747.

Goverover, Y., Genova, H., Smith, A., Chiaravalloti, N., \& Lengenfelder, J. (2016). Changes in activity participation following traumatic brain injury. Neuropsychological Rehabilitation, 27(4), 472-485.

Helmstaedter, C. (2002). Effects of chronic epilepsy on declarative memory systems. Progress in Brain Research, 135, 439-453.

Holbrook, M., \& Skilbeck, C. E. (1983). An activities index for use with stroke patients. Age and Ageing, 12, 166-170.

Isaac, C. L., Cushway, D., \& Jones, G. V. (2006). Is posttraumatic stress disorder associated with specific deficits in episodic memory? Clinical Psychology Review, 26, 939-955.

Jenkinson, N., Ownsworth, T., \& Shum, D. (2007). Utility of the Canadian Occupational Performance Measure in community-based brain injury rehabilitation. Brain Injury, 21(12), 1283-1294.

Law, M., Baptiste, S., Carswell-Opzoomer, A., McColl, M. A., Polatajko, H., \& Pollock, N. (1991). Canadian Occupational Performance Measure. Toronto: CAOT Publications ACE.

Law, M., Baptiste, S., McColl, M., Opzoomer, A., Polatajko, H., \& Pollock, N. (1990). The Canadian occupational performance measure: An outcome measure for occupational therapy. Canadian Journal of Occupational Therapy, 57(2), 82-87.

Lee, H., Smeaton, A. F., O’Connor, N., Jones, G., Blighe, M., Byrne, D., . . Gurrin, C. (2008). Constructing a SenseCam visual diary as a media process. Multimedia Systems Journal, 14(6), 341-349.

Lelliott, P. T., \& Fenwick, P. (1991). Cerebral pathology in pseudoseizures. Acta Neurologica Scandinavica, 83(2), $129-132$.

Loveday, C., \& Conway, M. A. (2011). Using SenseCam with an amnesic patient: Accessing inaccessible everyday memories. Memory, 19(7), 697-704.

Magliano, L., Fadden, G., Economou, M., Held, T., Xavier, M., Guarneri, M., ... Maj, M. (2000). Family burden and coping strategies in schizophrenia: 1-year follow-up data from the BIOMED I study. Social Psychiatry and Psychiatric Epidemiology, 35(3), 109-115.

Mair, A., Poirier, M., \& Conway, M. A. (2017). Supporting older and younger adults' memory for recent everyday events: A prospective sampling study using SenseCam. Consciousness and Cognition, 49, 190-202.

Mair, A., Poirier, M., \& Conway, M. A. (2019). Memory for staged events: Supporting older and younger adults' memory with SenseCam. Quarterly Journal of Experimental Psychology, 72(4), 717-728.

McDermott, L. M., \& Ebmeier, K. P. (2009). A meta-analysis of depressive severity and cognitive function. Journal of Affective Disorders, 119(1-3), 1-8.

Ormel, J., Rijsdijk, F. V., Sullivan, M., van Sonderen, E., \& Kempen, G. I. J. M. (2002). Temporal and reciprocal relatonship between IADL/ADL disability and depressive symptoms late in life. Journal of Gerontology: Psychological Sciences, 57B(4), 338-347.

Pauly-Takacs, K., Moulin, C. J. A., \& Estlin, E. J. (2011). SenseCam as a rehabilitation tool in a child with anterograde amnesia. Memory, 19(7), 705-712.

Seamon, J. G., Moskowitz, T. N., Swan, A. E., Zhong, B., Golembeski, A., Liong, C., .. Sosan, O. A. (2014). SenseCam reminiscence and action recall in memory-unimpaired people. Memory, 22(7), 861-866.

Sellen, A., Fogg, A., Aitken, M., Hodges, S., Rother, C. \& Wood, K. (2007). Do life-logging technologies support memory for the past? An experimental study using SenseCam. Proceedings of the SIGCHI Conference on Human Factors in Computing Systems, San Jose, California, USA, pp. 81-90. doi:10.1145/1240624.1240636

Shores, E. A., Marosszeky, J. E., Sandanam, J., \& Batchelor, J. (1986). Preliminary validation of clinical scale for measuring the duration of post-traumatic amnesia. The Medical Journal of Australia, 144, 569-572.

Silva, A. R., Pinho, M. S., Macedo, L., Moulin, C., Caldeira, S., \& Firmino, H. (2017). It is not only memory: Effects of SenseCam on improving well-being in patients with mild Alzheimer disease. International Psychogeriatrics, 29(5), $741-754$.

Silva, A. R., Pinho, M. S., Macedo, L., \& Moulin, C. J. A. (2016). A critical review of the effects of wearable cameras on memory. Neuropsychological Rehabilitation. doi: 10.1080/09602011.2015.1128450.

Silva, A. R., Pinho, S., Macedo, L. M. \& Moulin, C. J. (2013). Benefits of SenseCam review on neuropsychological test performance. American Journal of Preventative Medicine, 44(3), 302-307.

Sönderlund, H., Moscovitch, M., Kumar, N., Daskalakis, Z. J., Flint, A., Hermann, N., \& Levine, B. (2014). Autobiographical episodic memory in major depressive disorder. Journal of Abnormal Psychology, 123(1), 51-60.

Svanberg, J., \& Evans, J. J. (2014). Impact of SenseCam on memory, identity and mood in Korsakoff s syndrome: A single case experimental design study. Neuropsychological Rehabilitation, 24(3-4), 400-418.

Tulving, E., \& Pearlstone, Z. (1966). Availability versus accessibility of information in memory for words. Journal of Verbal Learning and Verbal Behavior, 5, 381-391.

Vakil, E., Greenstein, Y., Weiss, I., \& Shtein, S. (2019). The effects of moderate-to-severe traumatic brain injury on episodic memory: A meta-analysis. Neuropsychology Review, 29, 270-287. 
van Baalen, B., Odding, E., van Woensel, M. P. C., van Kessel, M., Roebroeck, M. E., \& Stam, H. J. (2006). Reliability and sensitivity to change of measurement instruments used in a traumatic brain injury population. Clinical Rehabilitation, 20, 686-700.

Vanderploeg, R. D., Donnell, A. J., Belanger, H. G., \& Curtiss, G. (2014). Consolidation deficits in traumatic brain injury: The core and residual verbal memory defect. Journal of Clinical and Experimental Neuropsychology, 36(1), 58-73.

Waters, D. (1995). Recovering from a depressive episode using the Canadian Occupational Performance Measure. Canadian Journal of Occupational Therapy, 62(5), 278-282.

Woodberry, E., Browne, G., Hodges, S., Watson, P., Kapur, N., \& Woodberry, K. (2015). The use of a wearable camera improves autobiographical memory in patients with Alzheimer's disease. Memory, 23(3), 340-349.

Table A1. Details of the 11 coding categories for transcribed memories

\begin{tabular}{|c|c|c|}
\hline Detail type & Description & Example \\
\hline \multirow[t]{2}{*}{ Episodic } & \multirow{2}{*}{$\begin{array}{l}\text { A stand-alone event-specific detail, describing a single aspect } \\
\text { of the event in question. Usually uttered as a single clause } \\
\text { or simple sentence. }\end{array}$} & 'I remember that I drove there' \\
\hline & & 'I drank a lot of water’ \\
\hline Semantic & $\begin{array}{l}\text { A detail describing general or personal semantic knowledge, } \\
\text { not specific to any one event or occasion. }\end{array}$ & 'I quit smoking 20 years ago’ \\
\hline Qualified & $\begin{array}{l}\text { Information about what probably happened, in the absence } \\
\text { of episodic recollection, given what is already known } \\
\text { either due to preserved semantic memory (I usually do x) } \\
\text { or information available in the photograph (It looks } \\
\text { like I'm doing x) }\end{array}$ & 'I probably ordered pizza' \\
\hline $\begin{array}{c}\text { External } \\
\text { event }\end{array}$ & $\begin{array}{l}\text { A stand-alone event-specific detail describing an aspect of a } \\
\text { different event, not the one in question. Importantly, this is } \\
\text { not reported as describing the event in question (in which } \\
\text { case it would be counted as incorrect, see below) }\end{array}$ & 'I went there once to watch football' \\
\hline Broad & $\begin{array}{l}\text { A detail pertaining to ongoing events, not specific to the event } \\
\text { in question. }\end{array}$ & $\begin{array}{l}\text { 'We're getting another dog at some } \\
\text { point' }\end{array}$ \\
\hline Cued & $\begin{array}{l}\text { A detail cued clearly by information provided by the camera } \\
\text { or the OT }\end{array}$ & $\begin{array}{l}\text { (for event titled, Getting takeaway): } \\
\text { 'We got takeaway' }\end{array}$ \\
\hline Recognised & $\begin{array}{l}\text { A detail clearly recognised from the photographs, but } \\
\text { evidencing more interpretation than a cued detail (above). } \\
\text { Usually describes what is happening in the photograph. }\end{array}$ & 'This is me signing the paperwork' \\
\hline Incorrect & $\begin{array}{l}\text { A detail that is demonstrably incorrect, usually because it is } \\
\text { incompatible with another detail known to be correct, or } \\
\text { with a high probability of being correct }\end{array}$ & \\
\hline \multirow[t]{3}{*}{ Repetition } & \multirow{3}{*}{$\begin{array}{l}\text { A detail or idea that is repeated more than once in a given } \\
\text { session. Only the first report of each idea is counted, } \\
\text { even if the wording is different on repetition. }\end{array}$} & $\begin{array}{l}\text { 'The girl wouldn't leave me alone' } \\
\ldots \text {.. 'she wouldn't leave me alone' }\end{array}$ \\
\hline & & Or \\
\hline & & $\begin{array}{l}\text { 'I didn't like the place' } \ldots \text { 'I } \\
\text { couldn't get out of there fast } \\
\text { enough' }\end{array}$ \\
\hline Reflection & $\begin{array}{l}\text { Present moment reflection on memory or the event } \\
\text { in question }\end{array}$ & $\begin{array}{l}\text { 'I haven't sorted out the paperwork } \\
\text { yet' }\end{array}$ \\
\hline Absence & A stated absence of memory & 'I don’t know how much I paid’ \\
\hline
\end{tabular}

Cite this article: Mair A and Shackleton R (2021). Using a wearable camera to support everyday memory following brain injury: a single-case study. Brain Impairment 22, 312-328. https://doi.org/10.1017/BrImp.2021.6 